\title{
BASE EXCESS, A MARKER OF CHRONIC HYPERCAPNIC RESPIRATORY FAILURE AND PREDICTOR OF SURVIVAL IN COPD
}

\author{
Stephan Budweiser, MD*, Rudolf A. Jörres, PhD*, Theresa Riedl*, Frank Heinemann, MD* and Michael Pfeifer, MD*, \\ *Center for Pneumology, Donaustauf Hospital, Donaustauf, Germany \\ ${ }^{*}$ Institute and Outpatient Clinic for Occupational and Environmental Medicine, Ludwig-Maximilians-University, Munich, Germany \\ "Dept of Internal Medicine II, University of Regensburg, Regensburg, Germany
}

WINNING ABSTRACT: We studied the role of base excess (BE) as marker of chronic hypercapnia and survival in patients with chronic obstructive pulmonary disease (COPD) and chronic hypercapnic respiratory failure (CHRF). Moreover, it was investigated whether the effects of non-invasive positive pressure ventilation (NPPV) on CHRF were reflected in BE and survival.

In 240 (160 without exacerbation) patients with COPD (mean \pm SD FEV1 $30.7 \pm 9.7 \%$ pred; PaCO $56.9 \pm 9.9$ mmHg) body-mass index (BMI), lung function, respiratory muscle function, blood gases and 6-minute walking distance (6-MWD) were assessed prior to initiation of NPPV. In addition, the changes of risk factors $6.3 \pm 2.9$ months after initiation of NPPV were evaluated.

Overall mortality during the follow-up time $(26.0 \pm 24.5$ months) was $34.6 \%$. Deaths resulted predominantly from respiratory causes (65.1\%); among those, respiratory failure was most frequent (85.2\%). Univariate analysis revealed BMI, FEV1, maximal inspiratory pressure $\left(\mathrm{PI}_{\max }\right)$, inspiratory load $\left(\mathrm{P}_{0.1}\right)$, haemoglobin, 6-MWD, hyperinflation (IC/TLC, RV/TLC), blood gases and $\mathrm{BE}$ to be associated ( $p<0.05$ each) with prognosis. In multivariate analyses, however, only BMI, RV/TLC and BE turned out to be independent cross-sectional predictors $(p<0.05)$. Kaplan-Meier analyses showed that BE had predictive value particularly in patients with $\mathrm{BMI} \geqslant 25 \mathrm{~kg} \cdot \mathrm{m}^{-2}, \mathrm{RV} / \mathrm{TLC} \geqslant 70 \%$ and $\mathrm{PaCO}_{2} \geqslant 57 \mathrm{mmHg}$. Furthermore, changes of $\mathrm{BMI}, \mathrm{RV} / \mathrm{TLC}$ and $\mathrm{BE}(\mathrm{p}<0.01)$ were associated with improved prognosis in severe hypercapnic COPD.

In patients with COPD and CHRF, BE was a prognostic marker for mortality, that was independent from other factors, particularly $\mathrm{PaCO}_{2}$. In addition, reversal of CHRF was reflected in $\mathrm{BE}$ and appeared to have an impact on prognosis.

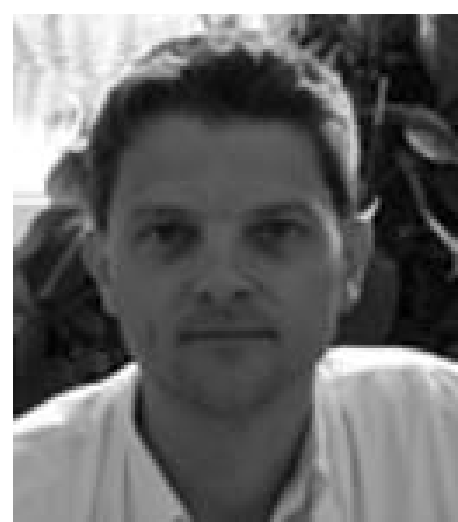

Stephan Budweiser

Center for Pneumology, Donaustauf Hospital, Donaustauf, Germany

\section{MY JOB AND THE UNIT IN WHICH I WORK}

The present investigation was performed by the Clinical Study Team of the Donaustauf Hospital, Donaustauf, Germany, which is associated with the University of Regensburg, Regensburg, Germany. Our institution is a large specialised regional centre for pneumology (120 in-patients), which covers the complete spectrum of respiratory and pulmonary medicine and treats $\sim 5,500$ patients $(4,500$ in-patients and 1,000 outpatients) each year. One major focus is acute and chronic respiratory failure, including invasive and noninvasive ventilation in various lung and chest diseases. We are also a supraregional centre for weaning from prolonged mechanical ventilation. Since the early 1990s, $>800$ patients have been adapted and discharged with home ventilation from our institution, and this number has increased during recent years to 150 patients each year (fig. 1).

In addition to my clinical work in pulmonary and intensive care medicine, I am currently assigned to a number of scientific projects dealing with patients suffering from chronic respiratory failure. I am also involved in multicentre, prospective controlled trials regarding novel advances in treatment of obstructive lung disease. The multidisciplinary team comprises specialised physicians, nurses, respiratory therapists and study nurses. There are also many scientific cooperations with the Ludwig-Maximilians-University of Munich, Germany.

\section{MY WINNING POSTER AS PART OF MY RESEARCH}

A part of my scientific work consists of the long-term observation of patients discharged with home mechanical ventilation. In particular, we evaluate the effects of noninvasive positive pressure ventilation (NPPV) $[1,2]$ and focus on optimising ventilator setting and treatment [3]. As the impact of nutritional status and body composition for long-term survival in chronic lung diseases has been convincingly shown [4], we have included nutritional assessment via bioelectrical impedance analysis within a routine clinical setting [5]. Moreover, we study the mechanisms of chronic ventilatory failure [6] and evaluate therapeutic procedures, such as respiratory muscle training [7] and cough-assist techniques.

We have access to a large database of patients with chronic hypercapnic respiratory failure (CHRF) and have focused our 


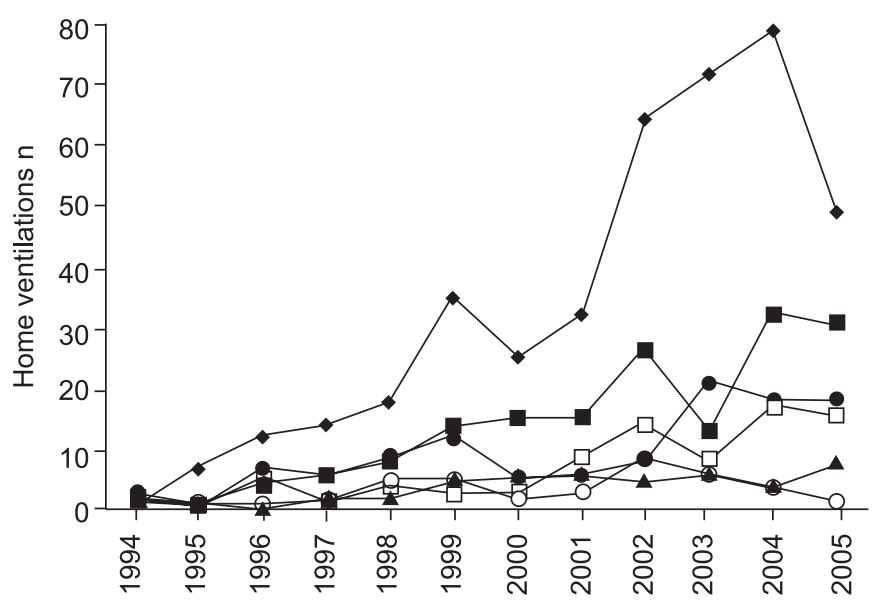

FIGURE 1. Distribution and change of the underlying disease in patients discharged with home mechanical ventilation $(n=854)$. pulmonary disease; $\mathbf{\square}$ : obesity hypoventilation syndrome; $\mathbf{0}$ : chest wall diseases; $\square$ : neuromuscular disorder; $\boldsymbol{\Delta}$ : overlap; $\bigcirc$ : others.

interest on long-term survival and prognostic factors. Although hypercapnia is often associated with advanced lung diseases, its predictive role per se for survival $[8,9]$ and the impact of a reduction in arterial carbon dioxide tension $\left(\mathrm{Pa}_{\mathrm{a}} \mathrm{CO}_{2}\right)$ by NPPV is still a topic of controversy [10]. Usually, CHRF is assessed via the determination of daytime $P a, C_{2}$, which is prone to fluctuations depending on the patient's momentary condition and inspiratory drive. In contrast, base excess (BE), representing the degree of metabolic compensation of respiratory acidosis, is probably a more stable marker due to the inertia of the compensatory mechanisms [11]. In the present study, we investigated the role of $\mathrm{BE}$ as a marker for $\mathrm{CHRF}$ and its predictive value for long-term mortality in patients with chronic obstructive pulmonary disease (COPD). In addition to established or recently proposed prognostic markers, such as forced expiratory volume in one second (FEV1), body mass index (BMI), 6-min walking distance (6-MWD), lung hyperinflation and laboratory parameters, we put special emphasis on BE. We investigated the predictive value of these markers either at baseline prior to NPPV or of their changes after initiation of NPPV.

The present study addressed long-term survival and prognostic factors in patients with COPD and CHRF under NPPV. It covered a 10-yr observation period and a mean follow-up time of $\sim 26$ months and is one of the largest investigations dealing with this issue.

\section{MY RESEARCH AS PART OF MY WORKING GROUP/ RESEARCH TEAM}

In accordance with previous studies [12], BMI was a strong predictor of mortality, as well as lung hyperinflation in terms of inspiratory capaciy/total lung capacity (TLC) and residual volume/TLC [13]. As the major novel finding of our study, we revealed $\mathrm{BE}$ to be a significant and consistent predictor of longterm mortality in patients with severe COPD and CHRF. Even more interesting seemed to be the results of conditional analyses of subgroups, which were either at particular risk or not, according to one of the previously known risk factors. This type of analysis revealed that BE was predictive only in some subgroups of patients, i.e. under the condition that certain other requirements were satisfied. We believe that this type of conditional analysis bears the potential for significant future refinement of risk scores, which in many cases are additive and do not adequately take into account interactions between risk factors.

Another conclusion from our data relates to the long-term benefit of NPPV. This has not been satisfactorily clarified [10] compared with the clear-cut results and corresponding recommendations in acute respiratory failure [14]. Beneficial effects of NPPV on blood gases, particularly a reduction of $\mathrm{Pa}, \mathrm{CO}_{2}$, have been demonstrated in patients with high inspiratory pressure levels $[1,15,16]$. While chronic hypercapnia implies poor survival, it is not clear whether its reversal, once hypercapnia has developed, results in an improved long-term survival. For this purpose, we compared survival between patients showing a reduction of $\mathrm{BE}$ by $\geqslant 40$ or $50 \%$ at follow-up (mean change) and patients showing no or smaller changes. In patients with $\mathrm{BE} \geqslant 10 \mathrm{mmol} \cdot \mathrm{L}^{-1}$, the reduction of BE after the start of NPPV was clearly associated with an improved long-term survival. However, as the analysis comprised a number of patients with exacerbation, the reduction of $\mathrm{Pa}_{1} \mathrm{CO}_{2}$ or $\mathrm{BE}$ could not be attributed to NPPV alone. Irrespective of this, our data indicate that BE might be helpful not only for the prediction but also for the assessment of benefits from interventions, such as NPPV.

\section{THE IMPACT OF MY WORK ON CLINICAL OR RESEARCH PRACTICE}

In summary, we concluded that $\mathrm{BE}$, an easily obtainable measure, is of value in the assessment of both mortality risk and treatment efficiency in patients with COPD and CHRF.

\section{REFERENCES}

1 Budweiser S, Heinemann F, Fischer W, Dobroschke J, Pfeifer M. Long-term reduction of hyperinflation in stable COPD by non-invasive nocturnal home ventilation. Resp Med 2005; 99: 976-984.

2 Budweiser S, Heinemann F, Meyer K, Wild P-J, Pfeifer M. Weight gain in cachectic COPD patients receiving noninvasive positive pressure ventilation. Resp Care 2006; 51: 126-132.

3 Budweiser S, Heinemann F, Fischer M, Dobroschke J, Wild P, Pfeifer M. Impact of ventilation parameters and duration of ventilator use on non-invasive home ventilation in restrictive thoracic disorders. Respiration 2006; 73: 488-494.

4 Vestbo J, Prescott E, Almdal T, et al. Body mass, fat free body mass and prognosis in COPD patients from a random population sample. Am J Respir Crit Care Med 2006; 173: 79-83.

5 Budweiser S, Meyer K, Heinemann F, Sroll Z, Lugauer E, Pfeifer M. Nutritional depletion and relationship to functional impairment in patients with chronic respiratory failure. Eur Respir J 2004; 20: Suppl. 48, S677.

6 Budweiser S, Heinemann F, Schroll S, Pfeifer M. Reduction of NTproBNP during long-term non-invasive positive pressure ventilation. Am J Respir Crit Care Med 2005; 2: A205.

7 Budweiser S, Moertl M, Jörres RA, Windisch W, Heinemann F, Pfeifer M. Respiratory muscle training in 
restrictive thoracic disease: A randomised controlled trial. Arch Phys Med Rehabil 2006; 87: 1559-1565.

8 Chailleux E, Fauroux B, Binet F, Dautzenberg B, Polu JM, for the Observatory Group of ANTADIR. Predictors of survival in patients receiving domiciliary oxygen therapy or mechanical ventilation. A 10-year analysis of ANTADIR Observatory. Chest 1996; 109: 741-749.

9 Aida A, Miyamoto K, Nishimura M, et al. Prognostic value of hypercapnia in patients with chronic respiratory failure during long-term oxygen therapy. Am J Respir Crit Care Med 1998; 158: 188-193.

10 Wijkstra PJ, Lacasse Y, Guyatt GH, et al. A metaanalysis of nocturnal non-invasive positive pressure ventilation in patients with stable COPD. Chest 2003; 124: 337-343.

11 Baum GL, Wolinsky E. Textbook of pulmonary diseases. Volume II. 5th Edn. London, Little, Brown and Company, 1994.

12 Celli BR, Cote CG, Marin JM, et al. The body-mass index, airflow obstruction, dyspnoea, and exercise capacity index in chronic obstructive pulmonary disease. $N$ Engl J Med 2004; 350: 1005-1012.

13 Casanova C, Torres JP de, Aguirre-Jaime A, Marin JM, Pinto-Plata V, Celli BR. Inspiratory-to-total lung capacity ratio predicts mortality in patients with chronic obstructive pulmonary disease. Am J Respir Crit Care Med 2005; 171: 591-597.

14 Brochard L, Mancebo J, Wysocki M, et al. Non-invasive ventilation for acute exacerbations of chronic obstructive pulmonary disease. N Engl J Med 1995; 333: 817-822.

15 Windisch W, Kostic S, Dreher M, Virchow JC, Sorichter S. Outcome of patients with stable COPD receiving controlled noninvasive positive pressure ventilation aimed at a maximal reduction of $\mathrm{Pa}, \mathrm{CO}_{2}$. Chest 2005; 128: 657-662.

16 Meecham-Jones DJ, Paul EA, Jones PW, Wedzicha JA. Nasal pressure support ventilation plus oxygen compared with oxygen therapy alone in hypercapnic COPD. Am J Respir Crit Care Med 1995; 152: 538-544. 